\title{
Effect of Microstructure on Cavitation during Hot Deformation of a Fine-Grained Aluminum-Magnesium Alloy as Revealed through Three-Dimensional Characterization
}

\begin{abstract}
JUNG-KUEI “BRIAN” CHANG, ERIC M. TALEFF, and PAUL E. KRAJEWSKI
The effect of microstructure on cavitation developed during hot deformation of a fine-grained AA5083 aluminum-magnesium alloy is investigated. Two-point correlation functions and threedimensional (3-D) microstructure characterization reveal that cavitation depends strongly on the mechanism that controls plastic deformation. Grain-boundary-sliding (GBS) creep produces large, interconnected cavities rapidly during plastic straining. Solute-drag (SD) creep produces isolated cavities with less total volume fraction at a given strain. The 3-D microstructure data reveal adjacency between various microstructural features. Cavities are observed to be preferentially adjacent to large $\mathrm{Al}_{6}(\mathrm{Mn}, \mathrm{Fe})$ particles and to $\mathrm{Mg}$-Si particles of all observed sizes. These data suggest that cavities preferentially nucleate at $\mathrm{Mg}-\mathrm{Si}$ particles and at large $\mathrm{Al}_{6}(\mathrm{Mn}, \mathrm{Fe})$ particles. This result may be applied to reduce cavitation in commercial hot-forming operations utilizing aluminum-magnesium alloys.
\end{abstract}

DOI: $10.1007 / \mathrm{s} 11661-009-0061-5$

(C) The Minerals, Metals \& Materials Society and ASM International 2009

\section{INTRODUCTION}

SUPERPLASTIC forming (SPF) is a traditional hotforming process for sheet materials that has been widely used in the aerospace and other transportation industries to form components with complex shapes. ${ }^{[1-3]}$ The SPF process utilizes high temperature and gas pressure to form superplastic sheet materials into a die. ${ }^{[2]}$ Quick-plastic forming (QPF), a recent advance in hot-forming technology, improves upon the SPF process by decreasing the forming temperature and increasing the forming rate, thus significantly increasing part production rates for the forming of shapes less complex than those possible with SPF. ${ }^{[4]}$ The QPF process is currently used for the commercial mass production of automobile body closure panels. ${ }^{[4]}$ Finegrained AA5083 sheet material is the most commonly used material for both the SPF and QPF processes. Understanding, predicting, and improving the forming limits of AA5083 sheet materials are critical to advancing QPF and SPF technologies.

The forming limits of fine-grained AA5083 sheet materials are controlled by both deformation and failure mechanisms, which depend on temperature, strain rate, and other factors. ${ }^{[5-7]}$ For SPF, grain-boundary-sliding (GBS) creep is widely recognized to be the dominant deformation mechanism in fine-grained AA5083 sheet. $^{[5,8-13]}$ Under GBS creep, the dominant failure

JUNG-KUEI "BRIAN" CHANG, Postdoctoral Fellow, and ERIC M. TALEFF, Professor, are with the Department of Mechanical Engineering, The University of Texas at Austin, Austin, TX 78712-0292. Contact e-mail: taleff@mail.utexas.edu PAUL E. KRAJEWSKI, GM

Technical Fellow, is with General Motors Corporation, Research and

Development, Warren, MI 48090-9055.

Manuscript submitted May 13, 2009.

Article published online October 27, 2009 mechanism of AA5083 is cavitation. ${ }^{[6]}$ For QPF, solutedrag (SD) creep begins to dominate deformation as temperature decreases and strain rate increases. ${ }^{[5,6]}$ Under SD creep, cavitation can still lead to failure, but flow localization (e.g., necking) becomes the controlling failure mechanism in some geometries. ${ }^{[6,7]}$ Differences in cavitation evolution with strain, including cavitation growth rate and cavity morphology, have been observed between deformation controlled by GBS creep and deformation controlled by SD creep. ${ }^{[6]}$ However, the initiation strains for cavitation are quite similar between GBS and SD creep deformation, ${ }^{[6]}$ suggesting that cavitation initiates in a similar manner under both deformation mechanisms.

Because of its great importance to formabilities, cavitation has been extensively studied in superplastic alloys ${ }^{[14-18]}$ and for AA5083, in particular. ${ }^{[13,19-23]}$ Most investigations documented in the literature used twodimensional (2-D) microstructure data, ${ }^{[13,19-21]}$ and only a few of these investigated cavitation under SD creep. Some work with three-dimensional (3-D) microstructure data is available, ${ }^{[22-24]}$ but data from those investigations do not typically achieve the resolutions of less than approximately $1 \mu \mathrm{m}$ necessary to distinguish microstructural features, such as small intermetallic particles, that might affect cavitation. Many reports exist of 2-D microstructure data indicating a specific cavity formed at a specific intermetallic particle, such as at the $\mathrm{Al}_{6}(\mathrm{Mn}, \mathrm{Fe})$ particles common in AA5083. ${ }^{[25-28]}$ Such evidence and further indirect evidence have led investigators to surmise that intermetallic particles are the primary nucleation sites for cavities during hot deformation of fine-grained AA5083 sheet. However, direct, quantitative observations supporting this hypothesis have not been available. This is because of inherent limitations in 2-D microstructure data, which cannot 
reveal cavity connectivity or adjacency of cavities with other microstructural features, except for infrequent, random, and isolated instances. However, 3-D microstructure data of sufficient resolution enable the complete characterization of connectivity and adjacency among microstructural features.

The goal of this investigation is to understand the effects of microstructural features and deformation mechanisms on the evolution of cavitation in finegrained AA5083 sheet under GBS creep and SD creep deformation. This is accomplished through the 3-D characterization of microstructures produced by hot deformation under each of these two deformation mechanisms. Both 3-D and 2-D microstructure data are used to quantitatively analyze the microstructural features associated with cavitation. Particular attention is given to the role of intermetallic particles.

\section{EXPERIMENT DESIGN}

Microstructures produced in fine-grained AA5083 sheet during deformation by GBS creep and SD creep should ideally be compared in the following two different conditions: (1) at identical true strains and (2) at identical cavity fractions. It is known from previous investigations $^{[5,6,29]}$ that each deformation mechanism can be produced at $450{ }^{\circ} \mathrm{C}$ simply by applying different strain rates. Thus, temperature was kept constant at $450{ }^{\circ} \mathrm{C}$ and strain rates were chosen, based upon prior experimental data, ${ }^{[5,6,29]}$ to be $3 \times 10^{-4} \mathrm{~s}^{-1}$ to produce deformation dominated by GBS creep and $3 \times 10^{-2} \mathrm{~s}^{-1}$ to produce deformation dominated by SD creep. Previous results for the evolution of cavity area fraction with strain under each of these test conditions ${ }^{[6]}$ shown in Figure 1, served as a guide in designing experiments for this investigation. The maximum true strain under uniaxial tension for the GBS test condition is approximately 1.3 , as measured from local area reduction. The

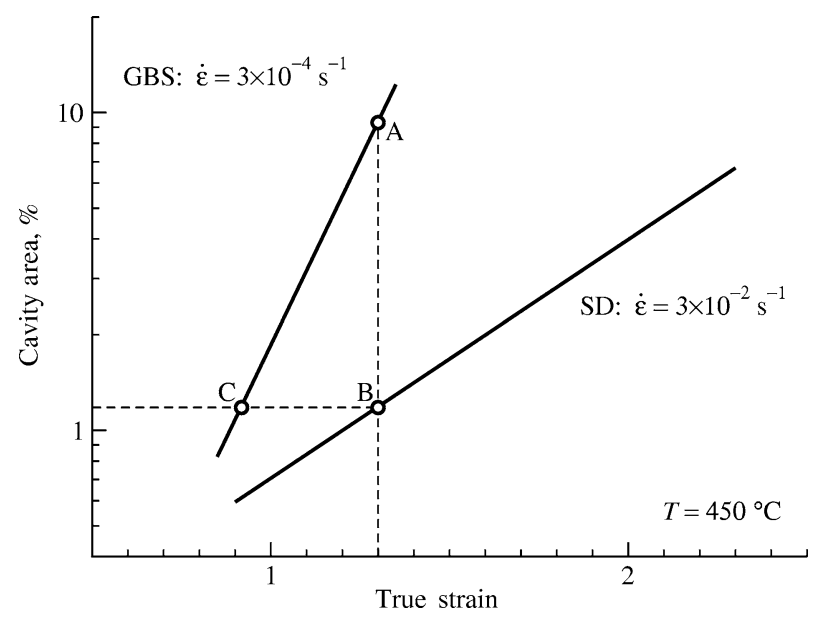

Fig. 1-Trends from data in Ref. 6 for cavity fraction as a function of tensile straining for a test temperature of $450{ }^{\circ} \mathrm{C}$ and true strain rates that produce deformation controlled by GBS creep $\left(3 \times 10^{-4} \mathrm{~s}^{-1}\right)$ and SD creep $\left(3 \times 10^{-2} \mathrm{~s}^{-1}\right)$. Points A, B, and C represent the three mechanical testing conditions chosen for investigation. cavity area fraction at this strain, shown by point $\mathrm{A}$ in Figure 1, is predicted to be approximately 10 pct. For this same local strain, the SD test condition will produce a cavity area fraction of approximately $1.2 \mathrm{pct}$, as shown by point $\mathrm{B}$ in Figure 1. Thus, points $\mathrm{A}$ and $\mathrm{B}$ represent two test conditions that can produce specimens with identical local true strains but different cavity contents because of deformation controlled by two different mechanisms. In order to determine a third test condition that produces the same cavity fraction as that at point B, but under GBS creep deformation, a horizontal line was drawn in Figure 1 from point B. That horizontal line intersects the GBS data line at point C. Point $\mathrm{C}$ occurs at a true strain of approximately 0.9 . Thus, points A, B, and C in Figure 1 represent the three test conditions chosen to produce specimens for microstructure observations.

\section{EXPERIMENTAL PROCEDURE}

A fine-grained AA5083 sheet material was studied in this investigation. This is the same as the material DC-C studied previously in References 5 and 6. This sheet material was hot and cold rolled from a homogenized, direct-chill casting to a final thickness of $1.2 \mathrm{~mm}$ and an approximately H18 temper. ${ }^{[30,31]}$ The chemical composition of this material is provided in Table I. After recrystallization, which occurs rapidly at $450{ }^{\circ} \mathrm{C}$, the lineal intercept grain size was measured, in accordance with ASTM E $112-96,{ }^{[32]}$ to be $6.5 \mu \mathrm{m}$.

Tensile coupons were machined from the as-received sheet, with the tensile axis parallel to the rolling direction, and were tested in tension at $450{ }^{\circ} \mathrm{C}$. Tensile coupons were dog-bone shaped and had a gage length of $25.4 \mathrm{~mm}$, a gage width of $6.0 \mathrm{~mm}$, a grip shoulder radius of $7.9 \mathrm{~mm}$, and a thickness of $1.2 \mathrm{~mm}$. Coupons were held in shoulder-loading grips, which effectively restricted deformation to the specimen gage region. Temperature was controlled to within $\pm 1.5^{\circ} \mathrm{C}$ along the entire specimen gage length, as measured from multiple type- $K$ thermocouples, using a three-zone resistance furnace. Both a screw-driven electromechanical testing frame and a servohydraulic testing frame were used for tensile testing. Both testing frames were computer controlled and used computerized data acquisition. Tensile tests were conducted by controlling displacement as a function of time, with several different displacement rates imposed in sequential steps to simulate a constant true strain rate. Tensile tests were conducted to failure or until a particular desired elongation was achieved. Two tensile tests were conducted to failure at $450{ }^{\circ} \mathrm{C}$, one at a true strain rate of $3 \times 10^{-2} \mathrm{~s}^{-1}$ and the other at $3 \times 10^{-4} \mathrm{~s}^{-1}$. A third tensile test at $450{ }^{\circ} \mathrm{C}$ and $3 \times 10^{-4} \mathrm{~s}^{-1}$ was conducted to

Table I. Composition of AA5083 Material in Weight Percent

\begin{tabular}{lcccccc}
\hline Element & $\mathrm{Mg}$ & $\mathrm{Mn}$ & $\mathrm{Fe}$ & $\mathrm{Si}$ & $\mathrm{Cu}$ & $\mathrm{Al}$ \\
\hline Weight percent & 4.50 & 0.76 & 0.20 & 0.15 & 0.03 & bal \\
\hline
\end{tabular}


a total elongation of 146 pct. Specimens for metallographic examination were sectioned from tested coupons, as represented in Figure 2. The specific locations from which to remove metallographic specimens were determined from local true strains calculated using measurements of area reduction along the gage length of each specimen. Metallographic specimens were removed from regions of tested coupons with local strains, as indicated in Table II.

Metallographic specimens were mounted on individual stainless steel polishing fixtures using a hot-melt wax adhesive with the sheet normal direction normal to the mounting surface. The tensile axis of each specimen was oriented along a known, marked direction. Each specimen was ground flat and parallel to the fixture using $\mathrm{SiC}$ abrasive. Three Vickers hardness indentations were then placed in each specimen to act as fiduciary marks during serial polishing. ${ }^{[33-35]}$ All observations in the optical microscope were made viewing along the sheet normal direction with the tensile axis horizontal. Specimens were polished to a final finish with $1-\mu \mathrm{m}$ diamond abrasive prior to serial polishing. Fifty serial polishing sections were made for each specimen by polishing with $1-\mu \mathrm{m}$ diamond abrasive using an Allied High Tech MultiPrep polishing system (Allied High Tech Products, Inc., Rancho Dominguez, CA). The average section depth was $0.5 \mu \mathrm{m}$ and the depth of individual sections

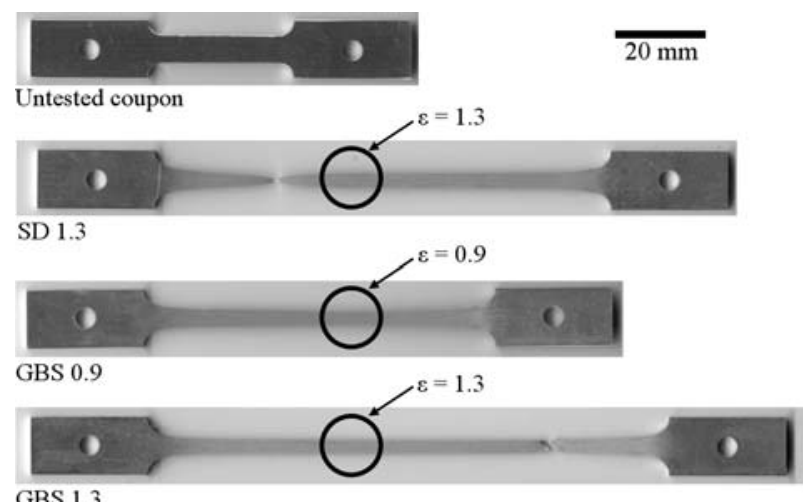

Fig. 2-Coupons tested at $450{ }^{\circ} \mathrm{C}$ under each of the three testing conditions with an untested coupon. Regions representative of those from which metallographic specimens were removed are circled.

Table II. Measurements from 3-D Microstructural Data of Three Specimens Tested at $450{ }^{\circ} \mathrm{C}$ Are Given as True Strain Rate $(\dot{\varepsilon})$, Local True Strain, Total Cavity Volume Fraction, Number of Cavities, and Average Individual Cavity Volume; Significant Figures Provided Represent the Approximate Degree of Certainty in Measurements

\begin{tabular}{llll}
\hline Measure & SD 1.3 & GBS 0.9 & GBS 1.3 \\
\hline$\dot{\varepsilon}\left(\mathrm{s}^{-1}\right)$ & $3 \times 10^{-2}$ & $3 \times 10^{-4}$ & $3 \times 10^{-4}$ \\
Local true strain & 1.3 & 0.9 & 1.3 \\
Cavity volume fraction & $1.35 \mathrm{pct}$ & $1.33 \mathrm{pct}$ & $11.3 \mathrm{pct}$ \\
Number of cavities & 604 & 227 & 316 \\
Average individual cavity & $109 \mu \mathrm{m}^{3}$ & $284 \mu \mathrm{m}^{3}$ & $1740 \mu \mathrm{m}^{3}$ \\
$\quad$ & & & \\
\hline
\end{tabular}

removed was controlled to within $\pm 0.2 \mu \mathrm{m}$. Each section was held parallel to within the resolution for measuring parallelism from the change in the Vickers indentation features during polishing. Digitized images were acquired from each polished section using an optical microscope at a magnification of 200 times. Digitized images were aligned to fiduciary marks and cropped to $540 \times 360 \mu \mathrm{m}$, represented as $3000 \times 2000$ pixels, in image-processing software. Supervised (manual) segmentation of features was conducted for each layer. These processed images were then stacked and further processed into 3-D data sets using the Reconstruct ${ }^{[36]}$ software package (J.C. Fiala, Department of Biology, Boston University, Boston, MA). Each $3-D$ data set was $540 \times 360 \times 25 \mu \mathrm{m}$ in size and contained 50 serial section planes. The resolution of the 3-D data sets is set by the voxel size at $0.18 \mu \mathrm{m}$ in the section planes and approximately $0.5 \mu \mathrm{m}$ perpendicular to those planes. Four distinct phases are represented in each 3-D data set, as follows: (1) Al matrix, (2) cavity, (3) $\mathrm{Al}_{6}(\mathrm{Mn}, \mathrm{Fe})$ intermetallic, and (4) $\mathrm{Mg}$-Si intermetallic. The two intermetallic particle types are easily

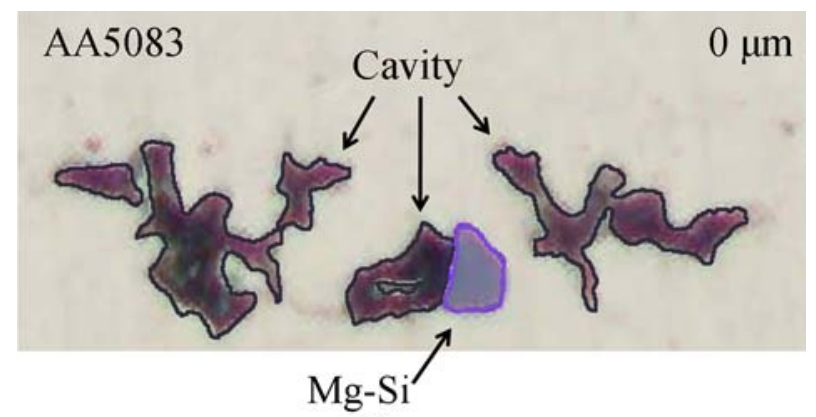

(a)

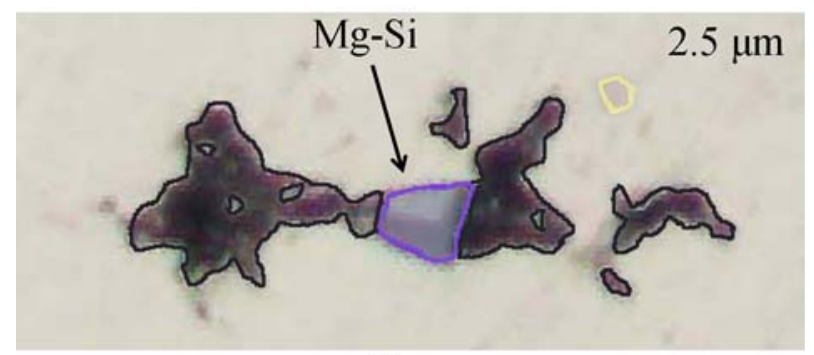

(b)

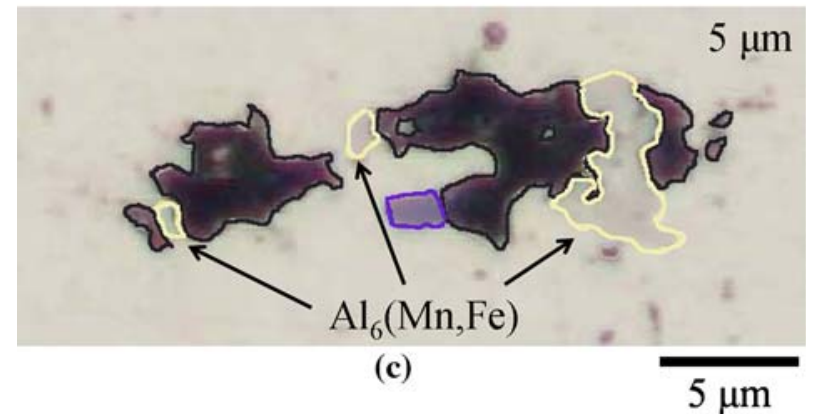

Fig. 3-(a) through (c) Three optical photomicrographs taken at three different polishing depths in specimen SD 1.3. The plane of (b) is $2.5 \mu \mathrm{m}$ below that of (a), and the plane of (c) is $5 \mu \mathrm{m}$ below that of (a). Four microstructural features can be distinguished: matrix, cavity, $\mathrm{Al}_{6}(\mathrm{Mn}, \mathrm{Fe})$ intermetallic, and $\mathrm{Mg}-\mathrm{Si}$ intermetallic. 
distinguished in optical photomicrographs of polished, unetched specimens, as shown in Figure 3. The $\mathrm{Al}_{6}(\mathrm{Mn}, \mathrm{Fe})$ intermetallic particles, common to 5000 series alloys, appear as a gray color different from that of the $\mathrm{Al}$ matrix. The $\mathrm{Mg}$-Si intermetallic particles have a light blue tint. These identifications were confirmed with energy-dispersive spectroscopy (EDS) in a scanning electron microscope (SEM), JEOL* JSM 5610 SEM

*JEOL is a trademark of Japan Electron Optics Ltd., Tokyo.

with an Oxford INCA200 EDS detector (Oxford Instruments, Abingdon, Oxfordshire, UK). Note that the specific stoichiometry of the $\mathrm{Mg}-\mathrm{Si}$ intermetallic particles was not determined in this study, but other investigators have most commonly observed $\mathrm{Mg}_{2} \mathrm{Si}^{\left[{ }^{[37-39]}\right.}$ with some reports of more complex chemistries. ${ }^{[40,41]}$

\section{RESULTS AND DISCUSSION}

Figure 4 reproduces the trend lines shown in Figure 1 for the logarithm of the cavity area fraction as a function of strain and shows the data of Reference 6, from which these trend lines were drawn. Also shown in Figure 4 are the volume fractions of cavities and the local true strains measured from the three metallographic specimens of the present study. These experimental results agree closely with those expected from the experimental design, i.e., points A, B, and C in Figure 1. Data were collected from each of these three specimens as 2-D serial section images from which 3-D microstructure reconstructions were produced. Both the 2-D and 3-D data sets were used to quantitatively characterize the microstructural features associated with cavitation. Figure 5 presents an example of a 3-D microstructure reconstruction of a cavity with adjacent intermetallic particles produced from the same region of specimen SD 1.3 as the 2-D serial sections shown in

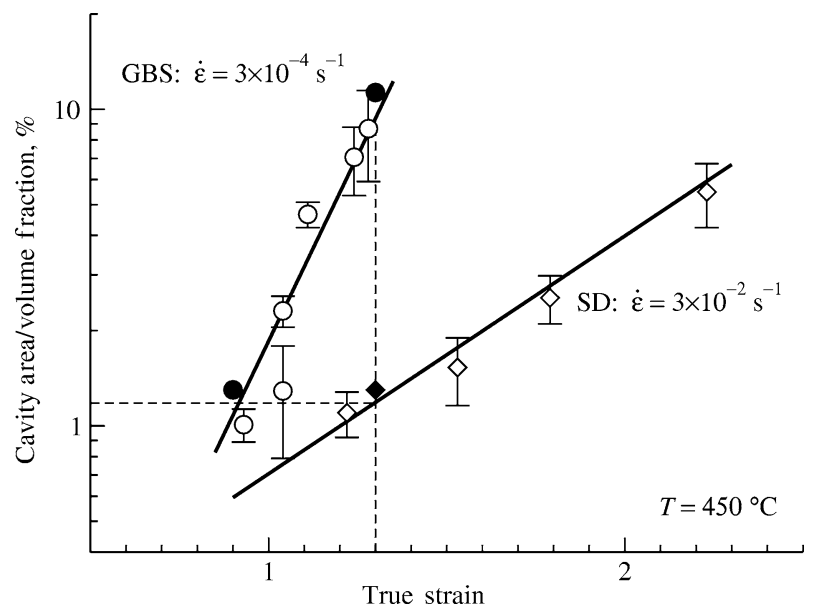

Fig. 4-Data for cavity content as a function of strain in a plot similar to that of Fig. 1, which was used in the design of experiments. Open symbols are data for cavity area fraction from Ref. 6. Filled symbols are cavity volume fractions measured from the three metallographic specimens examined in this investigation.
Figure 3. This 3-D model clearly demonstrates cavity connectivity and adjacency between the cavity and intermetallic particles, neither of which is fully revealed by the 2-D images of Figure 3. The reconstructed 3-D microstructure data provide useful information not available from the 2-D data sets, such as feature volume, 3-D morphology, connectivity, and adjacency. These aspects were evaluated in 3-D microstructure reconstructions from specimens SD 1.3, GBS 0.9 and GBS 1.3. The adjacency was determined using the algorithm encoded in the Reconstruct software package. ${ }^{[36]}$ In brief, this procedure measured adjacency from the manually produced object traces in each serial section. Measurements of the cavity volume fraction in each are given in Table II and were used to plot the filled data points in Figure 4. Also shown in Table II are the number of cavities observed and the average individual cavity volume calculated from the 3-D data volumes. What may appear to be discrete cavities in 2-D sections are reported as a single cavity when interconnected in the 3-D data set, i.e., multiple cavities may have interconnected during straining to become a single cavity. Note that these results include features that intersect the data volume surface, i.e., are not completely contained within the $3-\mathrm{D}$ volume observed. These results indicate that the GBS 1.3 specimen contains a cavity volume fraction of 11.3 pct, and both the GBS 0.9 and SD 1.3 specimens contain a cavity volume fraction of approximately 1.3 pct.

Two-point correlation functions are commonly used to mathematically represent correlations between microstructural features in 2-D metallographic data. ${ }^{[42-46]} \mathrm{A}$ two-point correlation function can represent the probability that a particular object exists at a specific distance and along a specific direction from a chosen location. Two-point correlations of this type ${ }^{[46]}$ were calculated for the relationships between the following pairs of microstructural features: (1) cavities and cavities (cavity/cavity), (2) $\mathrm{Al}_{6}(\mathrm{Mn}, \mathrm{Fe})$ particles and $\mathrm{Al}_{6}(\mathrm{Mn}, \mathrm{Fe})$ particles $\left(\mathrm{Al}_{6}(\mathrm{Mn}, \mathrm{Fe}) / \mathrm{Al}_{6}(\mathrm{Mn}, \mathrm{Fe})\right)$, (3) $\mathrm{Al}_{6}(\mathrm{Mn}, \mathrm{Fe})$ particles and cavities $\left(\mathrm{Al}_{6}(\mathrm{Mn}, \mathrm{Fe}) /\right.$ cavity), and (4) $\mathrm{Mg}$-Si particles and cavities ( $\mathrm{Mg}-\mathrm{Si} /$ cavity). The calculation of the two-point correlations between objects of the same phase, e.g., cavity/cavity or $\mathrm{Al}_{6}(\mathrm{Mn}, \mathrm{Fe}) / \mathrm{Al}_{6}(\mathrm{Mn}, \mathrm{Fe})$,

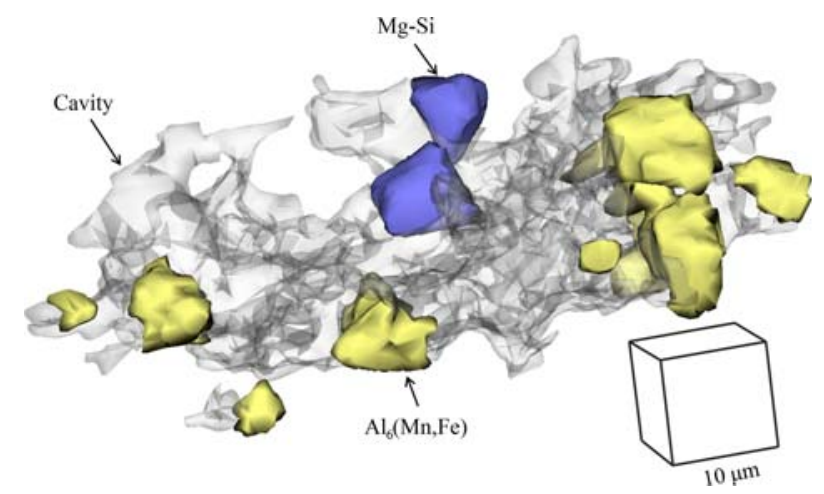

Fig. 5-3-D microstructure reconstruction for region of specimen SD 1.3 from which the optical photomicrographs in Fig. 3 were acquired. This visualization clearly demonstrates adjacency of both intermetallic particle types with one continuous cavity. 
involves details worth noting. The first step in calculating the two-point correlation function is to choose a point, a pixel from a 2-D image, that lies on a particular object (phase). A second point (pixel) is then chosen at another location and a calculation is made for these two points. The two-point correlation function is essentially an accumulation of such calculations over an area sufficient in size to provide statistical significance to the result. When the first and second points lie on the same phase, a decision must be made in the calculation process. This decision depends on whether the two points lying on the same phase also lie on separate objects, to the extent to which it is possible to distinguish separate objects in a 2-D image. Thus, calculation of the two-point correlation function between points within the same phase can do one of the following: (1) include all point pairs without regard to the specific objects included, identifying only the phases, or (2) exclude those point pairs that lie on the same object. Each of these methods produces different information, and two-point correlation functions were calculated by both methods for this study.

The results of the first two-point correlation function calculation method, which includes all point pairs in the calculation, are shown as contour plots in Figure 6. In this figure, dashed contours represent locations of completely random correlation, i.e., no meaningful correlation between objects, that were calculated by averaging the probabilities at all locations. The dashed contours are, thus, a value of unity for the normalized

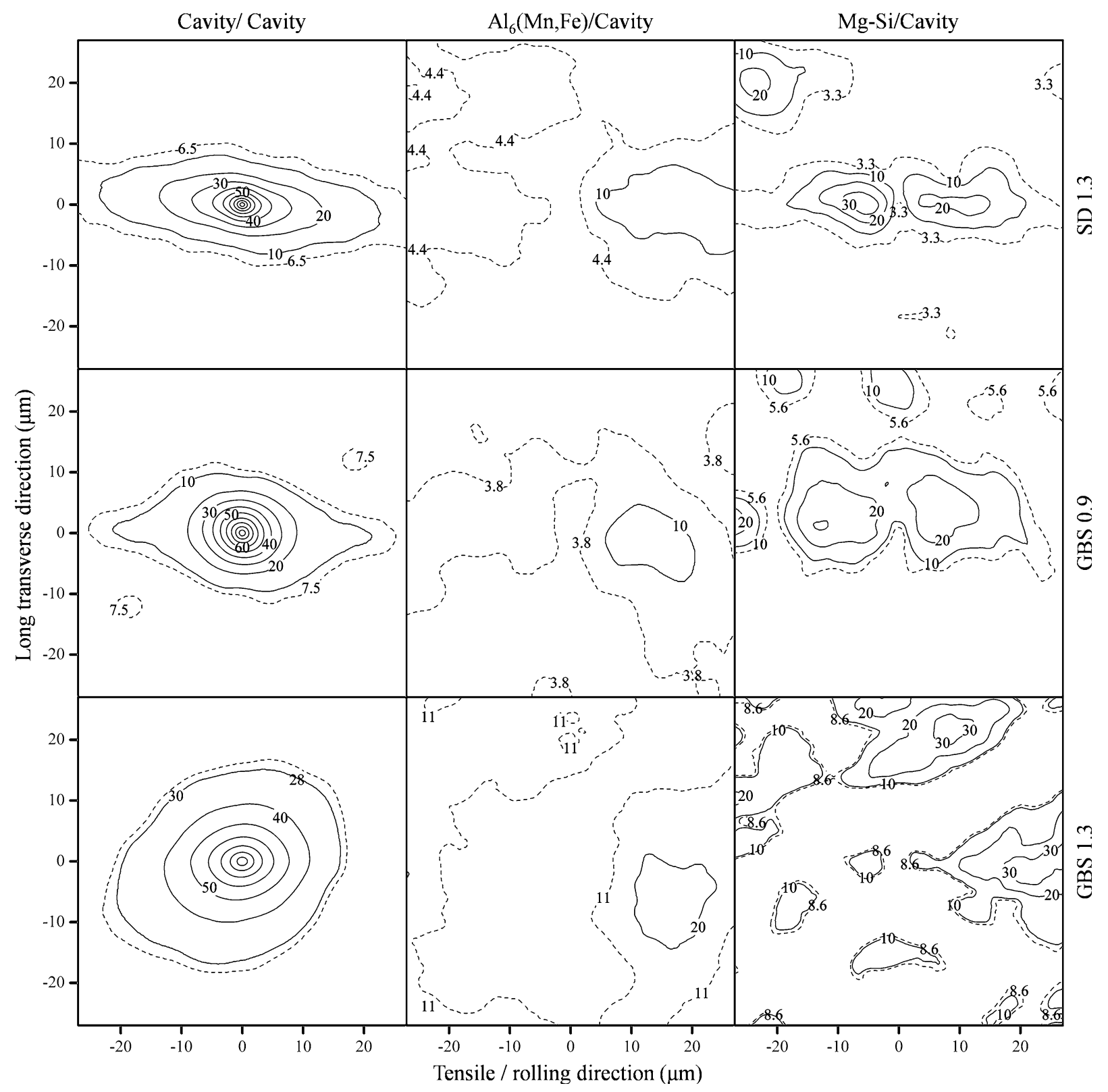

Fig. 6 - Contour plots of probability in percent for two-point correlations of (left) cavity/cavity, (middle) $\mathrm{Al}{ }_{6}(\mathrm{Mn}, \mathrm{Fe}) /$ cavity, and (right) $\mathrm{Mg}$-Si/ cavity spatial relationships in 2-D photomicrographs from approximately the middle of metallographic specimens (top) SD 1.3, (middle) GBS 0.9, and (bottom) GBS 1.3. Dashed contours represent the boundary of random correlations, i.e., no meaningful correlation between objects. 
two-point correlation function, i.e., $\left\langle P_{i j}\right\rangle=1$. Numbers shown on the contours of Figure 6 are probabilities in percent. The following correlation characteristics are revealed in Figure 6. In the SD 1.3 specimen, cavities are elongated and aligned along the tensile direction. In the GBS 0.9 specimen, cavities are rounded and somewhat aligned along the tensile direction. In the GBS 1.3 specimen, cavities are rounded and no alignment between cavities is observed. In the $\mathrm{Al}_{6}(\mathrm{Mn}, \mathrm{Fe}) /$ cavity correlation contour plots, very weak evidence for $\mathrm{Al}_{6}(\mathrm{Mn}, \mathrm{Fe})$ particles aligning with cavities along the tensile axis is observed in the SD 1.3 and GBS 0.9 specimens, but no such alignment is observed in the GBS 1.3 specimen. The $\mathrm{Mg}$-Si/cavity correlation contour plots show that $\mathrm{Mg}$-Si particles more strongly align with cavities along the tensile axis in the SD 1.3 and GBS 0.9 specimens than do $\mathrm{Al}_{6}(\mathrm{Mn}, \mathrm{Fe})$ particles, but no alignment is observed in the GBS 1.3 specimen. These results suggest that particles, particularly $\mathrm{Mg}$-Si intermetallic particles, are interacting with cavities under some testing conditions. However, further details of the relationships between particles and cavities are not available from these 2-D data.

In order to elucidate the degree to which microstructural features are aligned along the tensile axis in the SD 1.3 specimen, two-point correlations were calculated by the second method, which excludes point pairs lying on the same object. This calculation reveals the alignment between objects and effectively excludes the effect of the individual object shape. These calculations for the correlations between cavities, designated cavity/separate cavity, and $\mathrm{Al}_{6}(\mathrm{Mn}, \mathrm{Fe})$ particles, designated $\mathrm{Al}_{6}(\mathrm{Mn}, \mathrm{Fe}) /$ separate $\mathrm{Al}_{6}(\mathrm{Mn}, \mathrm{Fe})$, are presented in Figure 7. Figure 7(a) reveals that separate cavities are strongly aligned along the tensile axis in the SD 1.3 specimen. Because the tensile axis is parallel to the rolling direction in the specimens studied, it is possible that stringers of intermetallic particles aligned with the rolling direction might affect the alignment of cavities. Figure 7(b) reveals the alignment of $\mathrm{Al}_{6}(\mathrm{Mn}, \mathrm{Fe})$ particles with the tensile (rolling) direction. However, the alignment of cavities with the tensile direction in the SD 1.3 specimen (Figure 7(a)) is stronger than that of
$\mathrm{Al}_{6}(\mathrm{Mn}, \mathrm{Fe})$ particles with the tensile (rolling) direction (Figure 7(b)). Thus, the alignment of cavities along the tensile axis is a result of more than intermetallic particle stringers and can be largely attributed to the SD creep mechanism. Somewhat remarkably, the degree of cavity alignment with the tensile direction in the GBS 0.9 specimen (Figure 7(c)), is very similar to that of the $\mathrm{Al}_{6}(\mathrm{Mn}, \mathrm{Fe})$ particles (Figure 7(b)). This suggests that $\mathrm{Al}_{6}(\mathrm{Mn}, \mathrm{Fe})$ particles are nucleation sites for cavities, at least in GBS creep deformation. The lesser number of $\mathrm{Mg}$-Si particles makes the meaningful determination of alignment for this particle type difficult.

Visualizations of 3-D microstructures reconstructed using serial-section data from the three metallographic specimens are shown in Figure 8. Each of the 3-D reconstructions reproduces microstructural features within a volume of $540 \times 360 \times 25 \mu \mathrm{m} \quad(3000 \times$ $2000 \times 50$ voxels). The rolling direction is horizontal in Figure 8, and the long-transverse direction is vertical. Three different microstructural features are shaded in Figure 8 as follows: (1) cavities, (2) $\mathrm{Al}_{6}(\mathrm{Mn}, \mathrm{Fe})$ intermetallic particles, and (3) $\mathrm{Mg}$-Si intermetallic particles. Each feature type is distinguished in Figure 8 by a color shown in the color key at the bottom of that figure. The regions not colored are Al-matrix material. The resolution of these 3-D reconstructions is limited by the pixel size of acquired 2-D images $(0.18 \mu \mathrm{m} /$ pixel $)$ and the spacing of serial sections, which is, on average, $0.5 \mu \mathrm{m}$ between each serial section. These 3-D microstructure reconstructions provide sufficient detail to qualitatively and quantitatively characterize most of the microstructural features that control cavitation. The most important microstructural feature not included in these data is the grain boundary, which is a challenge to experimental techniques left for future studies.

The left column of images in Figure 8 displays all the microstructural features contained in the 3-D reconstructions. The cavity sizes, morphologies, and distributions are clearly different between the three specimens. Some of these differences are quantified in Table II. Both the SD 1.3 and GBS 0.9 specimens contain a similar volume fraction of cavities, approximately $1.3 \mathrm{pct}$, but contain very different numbers of cavities

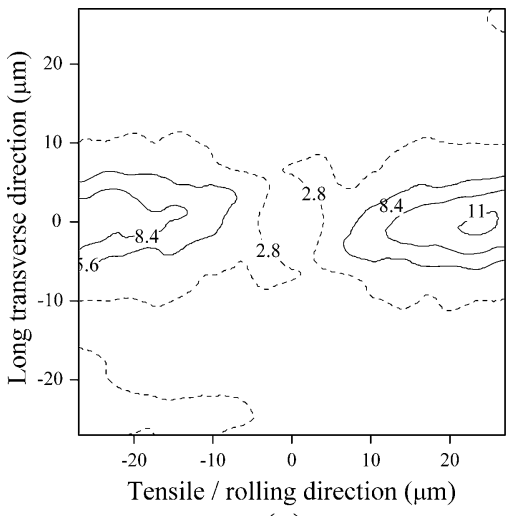

(a)

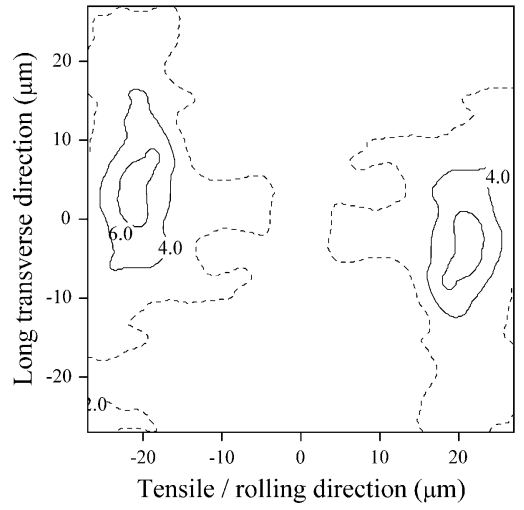

(b)

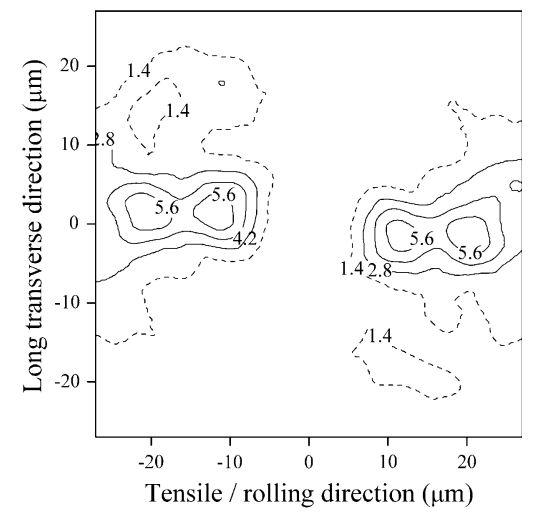

(c)

Fig. 7-Contour plots of probability in percent for two-point correlations calculated excluding point pairs lying on the same object in the SD 1.3 specimen for $(a)$ cavity/separate cavity and $(b) \mathrm{Al}_{6}(\mathrm{Mn}, \mathrm{Fe}) /$ separate $\mathrm{Al}_{6}(\mathrm{Mn}, \mathrm{Fe})$, and in the GBS 0.9 specimen for $(c)$ cavity/separate cavity. 


\section{All microstructural features}

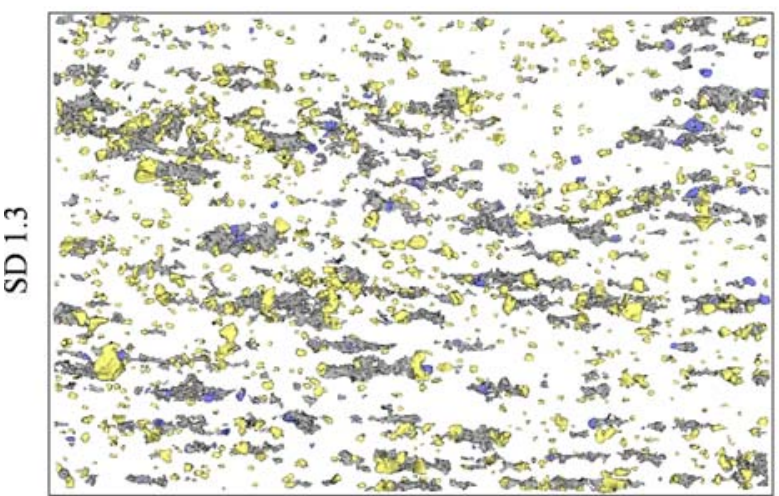

(a)

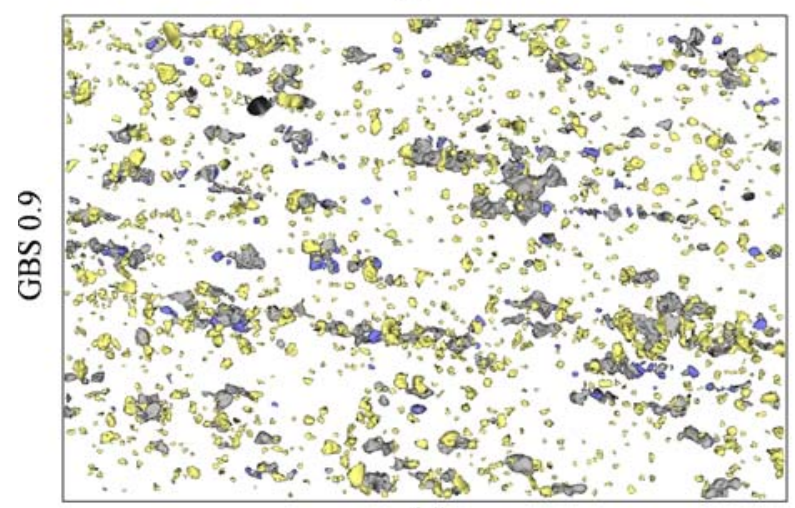

(c)

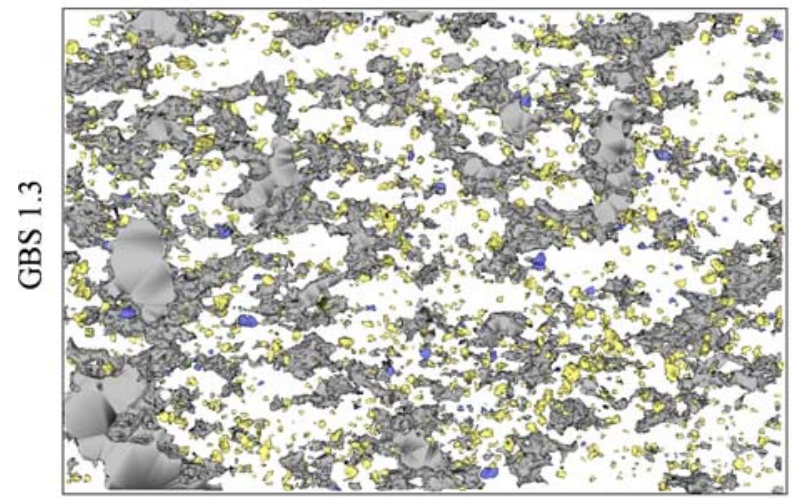

(e)

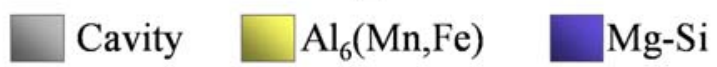

Intermetallic particles only

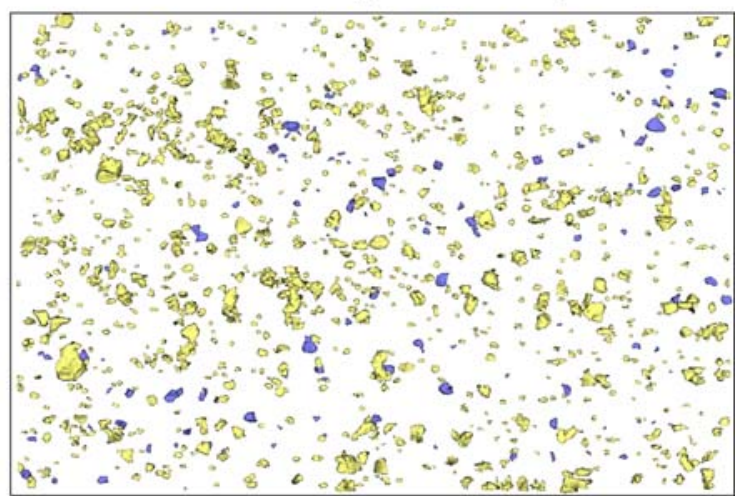

(b)

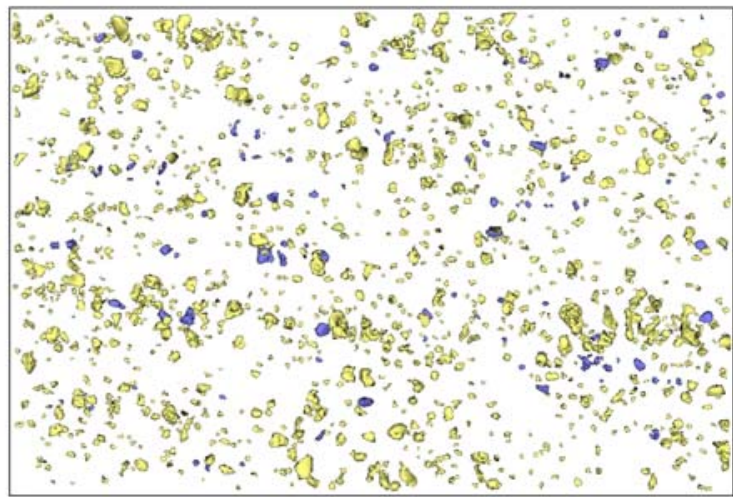

(d)
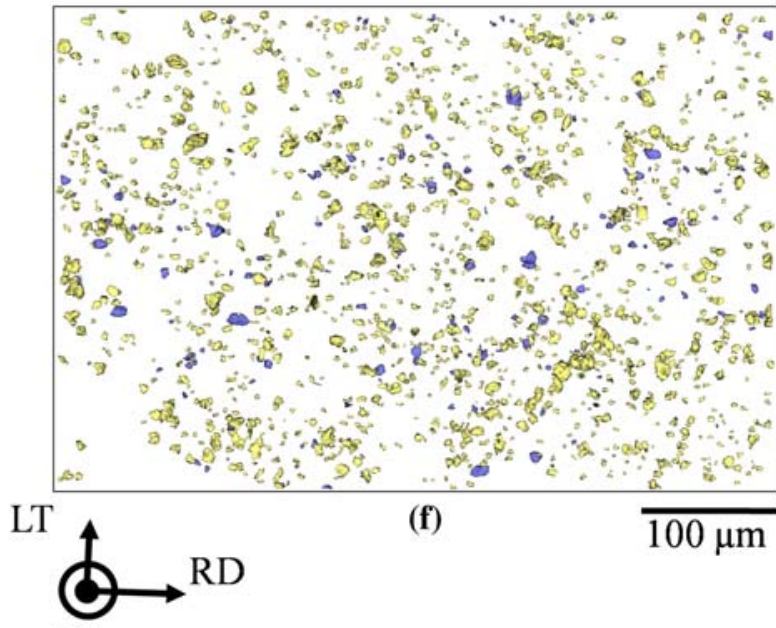

(f)

$\overline{100 \mu \mathrm{m}}$

Fig. 8-Projections of 3-D microstructure reconstructions from serial sections of (top) SD 1.3, (middle) GBS 0.9, and (bottom) GBS 1.3 specimen data sets. In the left column, all distinguishable objects are displayed. In the right column, only intermetallic particles are displayed.

for the same observed volumes, 604 cavities vs 227 cavities, respectively. This results in very different average individual cavity sizes between the SD 1.3 and GBS 0.9 specimens, as is shown in Table II. Qualitative observation of Figure 8(a) reveals cavities elongated and aligned along the tensile (rolling) direction in the SD 1.3 specimen, which is consistent with the two-point correlation functions shown in Figures 6 and 7. Observation of Figure 8(c) reveals cavities that are more equiaxed and somewhat aligned along the tensile (rolling) direction in the GBS 0.9 specimen, which is consistent with the two-point correlation functions shown in Figures 6 and 7. The GBS 1.3 specimen contains more than 8 times the volume fraction of cavities that the specimen GBS 0.9 contains, but it contains only 40 pct more cavities by number. This results in an average individual cavity size in the GBS 1.3 specimen which is at least 6 times that of the GBS 0.9 specimen, as is shown in Table II. The small increase in cavity numbers between specimens GBS 0.9 and GBS 1.3 suggests that much of 
the cavity volume increase under GBS deformation between strains of 0.9 and 1.3 is a result of individual cavity growth and coalescence of cavities. This is consistent with qualitative observations from Figure 8(e), which shows large, continuous cavities that frequently interconnect. The alignment of cavities observed in the GBS 0.9 specimen (Figure 8(c)) is not apparent in the GBS 1.3 specimen (Figure 8(e)). This is consistent with the two-point correction functions presented in Figure 6. However, several small cavities are still clearly observed in Figure 8(e), supporting the concept of the continuous nucleation of new cavities during deformation. ${ }^{[47]}$ This is also consistent with the increase in cavity numbers between the strains of 0.9 and 1.3 and is consistent with cavity size distribution measurements not shown here.

The right column of images in Figure 8 displays only intermetallic particles contained in the 3-D reconstructions. The 3-D spatial distributions and particle size distributions of both $\mathrm{Al}_{6}(\mathrm{Mn}, \mathrm{Fe})$ and $\mathrm{Mg}-\mathrm{Si}$ type intermetallic particles appear very similar between the three specimens. The particle size is presented as the equivalent spherical diameter, to allow for easy comparison with data obtained from standard 2-D metallographic measurements. The data in Table III indicate that all three specimens contain similar numbers of each intermetallic particle type. The ratio of $\mathrm{Al}_{6}(\mathrm{Mn}, \mathrm{Fe})$ to $\mathrm{Mg}$-Si particles is approximately 10:1 for all specimens. Note that particles that intersect the data volume surface and those with equivalent spherical diameter sizes of less than $1.75 \mu \mathrm{m}$ are not included in this analysis. The $\mathrm{Al}_{6}(\mathrm{Mn}, \mathrm{Fe})$ and $\mathrm{Mg}-\mathrm{Si}$ particle size distributions measured from the observed 3-D data sets are shown in Figure 9. The particle size distributions for $\mathrm{Al}_{6}(\mathrm{Mn}, \mathrm{Fe})$ particles (Figure 9(a)) and $\mathrm{Mg}$-Si particles (Figure 9(b)) in the three metallographic specimens are almost identical for a given particle type. The consistencies of the particle densities and the distributions between specimens indicates that cavitation does not significantly alter these quantities from the values in the starting material, at least to within the strain and cavity volume fraction represented in specimen GBS 1.3.

Detailed qualitative examination of the 3-D visualizations shown in Figure 8 suggests a large fraction of intermetallic particles adjacent to cavities. This observation was further investigated in a quantitative manner by measuring the type, number, and size of intermetallic particles adjacent to cavities and of intermetallic particles not adjacent to cavities. As shown in Table III, the cavity adjacency fraction, the fraction of particles adjacent to cavities, for $\mathrm{Mg}$-Si particles is much larger than that of $\mathrm{Al}_{6}(\mathrm{Mn}, \mathrm{Fe})$ particles. From 67 to 84 pct of $\mathrm{Mg}-\mathrm{Si}$ particles are adjacent to cavities, but only 11 to 22 pct of $\mathrm{Al}_{6}(\mathrm{Mn}, \mathrm{Fe})$ particles are adjacent to cavities.

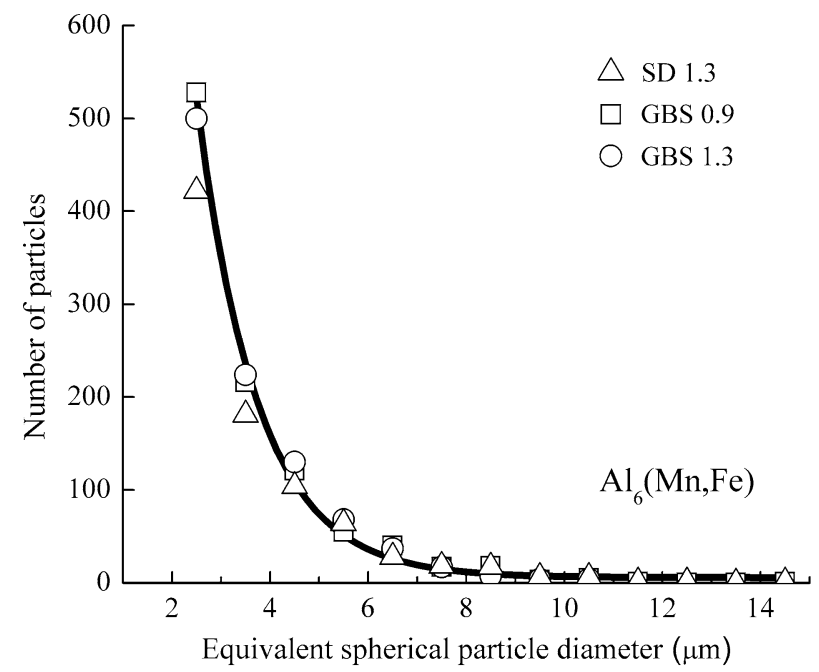

(a)

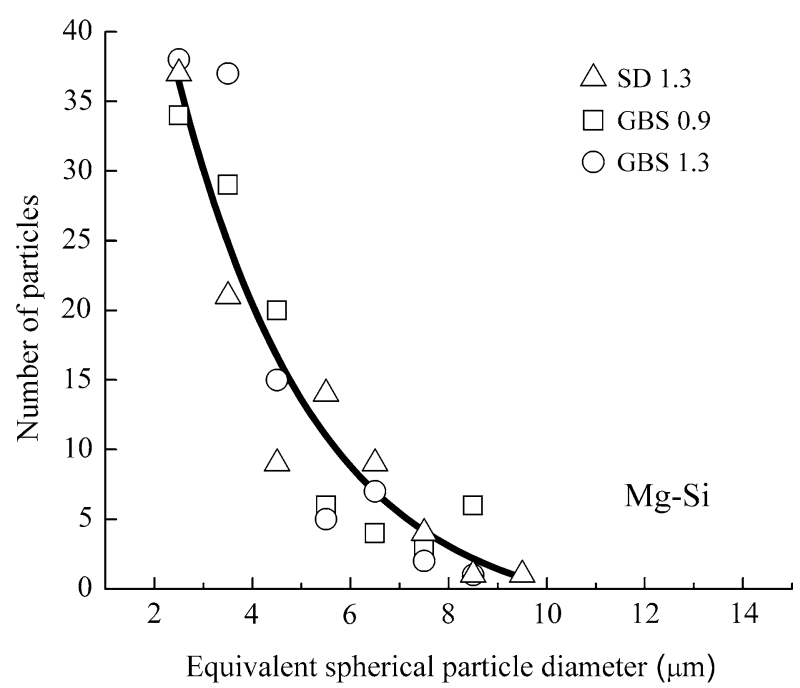

(b)

Fig. 9-Intermetallic particle size distributions for (a) $\mathrm{Al}_{6}(\mathrm{Mn}, \mathrm{Fe})$ and (b) $\mathrm{Mg}-\mathrm{Si}$.

Table III. Measurements from 3-D Microstructural Data for Number of Particles, Percentage of Particles Adjacent to Cavities, Average Size of Particles Adjacent to Cavities, and Average Size of Particles Not Adjacent to Cavities Are Provided as a Function of Particle Type in Each 3-D Data Set; Standard Deviation of Average Size of Particles Is Provided for Each Measurement; Size of Particles Is Provided as Equivalent Spherical Diameter

\begin{tabular}{|c|c|c|c|c|c|c|}
\hline \multirow[b]{2}{*}{ Measure } & \multicolumn{2}{|c|}{ SD 1.3} & \multicolumn{2}{|c|}{ GBS 0.9} & \multicolumn{2}{|c|}{ GBS 1.3} \\
\hline & $\mathrm{Al}_{6}(\mathrm{Mn}, \mathrm{Fe})$ & $\mathrm{Mg}-\mathrm{Si}$ & $\mathrm{Al}_{6}(\mathrm{Mn}, \mathrm{Fe})$ & $\mathrm{Mg}-\mathrm{Si}$ & $\mathrm{Al}_{6}(\mathrm{Mn}, \mathrm{Fe})$ & $\mathrm{Mg}-\mathrm{Si}$ \\
\hline Number of particles & 1053 & 109 & 1171 & 108 & 1157 & 117 \\
\hline Cavity adjacency (pct) & 16 & 84 & 11 & 67 & 22 & 70 \\
\hline Average size of particles adjacent to cavities $(\mu \mathrm{m})$ & $5.5 \pm 2.4$ & $4.0 \pm 1.8$ & $5.3 \pm 2.4$ & $4.2 \pm 1.9$ & $4.7 \pm 1.8$ & $3.8 \pm 1.5$ \\
\hline Average size of particles not adjacent to cavities $(\mu \mathrm{m})$ & $2.9 \pm 1.1$ & $2.7 \pm 1.4$ & $3.0 \pm 1.2$ & $3.2 \pm 1.1$ & $2.8 \pm 1.0$ & $2.8 \pm 0.8$ \\
\hline
\end{tabular}


Note that only particles with an equivalent spherical diameter larger than $1.75 \mu \mathrm{m}$ are considered for values shown in Table III. Both types of intermetallic particles are more likely to be adjacent to cavities as the particle diameter increases. The average equivalent spherical diameter of $\mathrm{Al}_{6}(\mathrm{Mn}, \mathrm{Fe})$ intermetallic particles adjacent to cavities is approximately 70 pet larger than that of $\mathrm{Al}_{6}(\mathrm{Mn}, \mathrm{Fe})$ particles not adjacent to cavities. For $\mathrm{Mg}-\mathrm{Si}$ intermetallic particles adjacent to cavities, the average equivalent spherical diameter is approximately $40 \mathrm{pct}$ larger than that of $\mathrm{Mg}-\mathrm{Si}$ particles not adjacent to cavities. These results indicate that cavities more frequently occur next to large intermetallic particles during straining in all specimens, and cavities occur preferentially at $\mathrm{Mg}$-Si particles.

Figure 10 shows the fraction of particles adjacent to cavities as a function of the equivalent spherical diameter for $\mathrm{Al}_{6}(\mathrm{Mn}, \mathrm{Fe})$ and $\mathrm{Mg}-\mathrm{Si}$ particles. Only

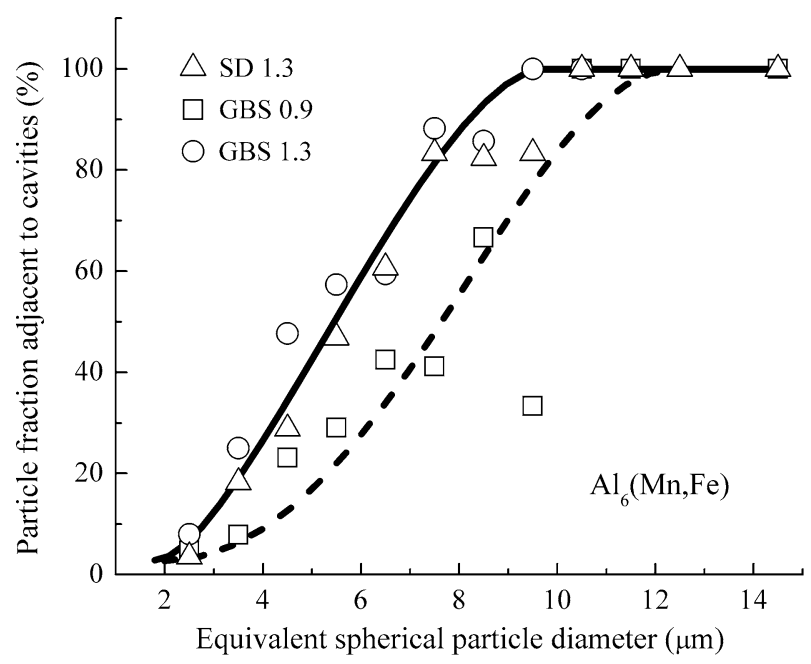

(a)

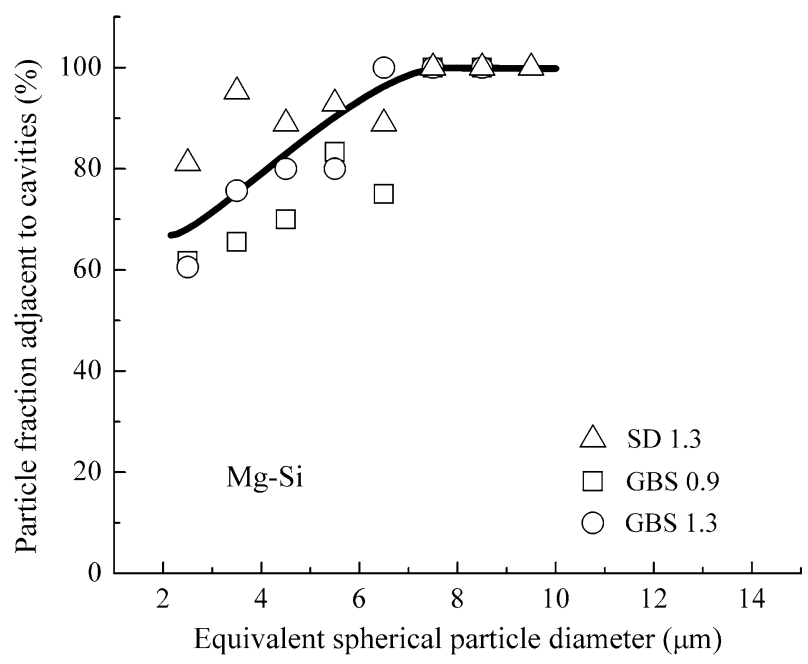

(b)

Fig. 10-Fraction of particles adjacent to cavities as a function of equivalent spherical particle diameter for $(a) \mathrm{Al}_{6}(\mathrm{Mn}, \mathrm{Fe})$ and $(b)$ $\mathrm{Mg}-\mathrm{Si}$ intermetallic particles. In (a), the solid line represents the trend of the SD 1.3 and GBS 1.3 data, while the dashed line represents the trend of the GBS 0.9 data. particles with equivalent spherical diameters of $2 \mu \mathrm{m}$ and greater are considered for the distributions shown in Figure 10, and the bin size of distributions presented is $1 \mu \mathrm{m}$. For both particle types, an increase in the particle size increases the probability of cavity adjacency. This trend is significantly more pronounced for $\mathrm{Al}_{6}(\mathrm{Mn}, \mathrm{Fe})$ particles. While nearly 100 pet of $\mathrm{Al}_{6}(\mathrm{Mn}, \mathrm{Fe})$ particles with an equivalent spherical diameter of $10 \mu \mathrm{m}$ and greater reside adjacent to a cavity, less than 10 pct at the smallest measured diameters ( 2 to $3 \mu \mathrm{m}$ ) reside adjacent to a cavity. While $100 \mathrm{pct}$ of $\mathrm{Mg}$-Si particles with a diameter of $7 \mu \mathrm{m}$ or greater reside adjacent to a cavity, more than $60 \mathrm{pct}$ at the smallest measured diameters ( 2 to $3 \mu \mathrm{m}$ ) also reside adjacent to a cavity. This strongly suggests that $\mathrm{Mg}$-Si particles are more prone to nucleate cavities than are $\mathrm{Al}_{6}(\mathrm{Mn}, \mathrm{Fe})$ particles, particularly at small particle sizes. However, because there are approximately 10 times as many $\mathrm{Al}_{6}(\mathrm{Mn}, \mathrm{Fe})$ particles as $\mathrm{Mg}-\mathrm{Si}$ particles, it is clear that both particle types must play important roles in the cavitation process.

\section{CONCLUSIONS}

This experimental investigation provides new insight into the nature of cavitation evolution in AA5083 sheet materials deformed at elevated temperatures and strain rates similar to those used in the SPF and QPF commercial forming processes. Cavitation developed under conditions promoting GBS creep is distinctly different from cavitation developed under conditions promoting SD creep. The GBS creep produces cavities that grow quickly with strain and develop into very large, interconnected cavity structures. The SD creep produces a larger number of smaller cavities that align along the tensile direction, which is identical to the rolling direction in this study, and have a lesser propensity to interconnect. The initiation of cavitation appears to be similar between both GBS and SD creep deformation, and initiation was previously shown to occur at a similar strain for both deformation mechanisms. Taking the adjacency between intermetallic particles and cavities as an indication of cavity nucleation at particles leads to the following conclusions. Large $\mathrm{Al}_{6}(\mathrm{Mn}, \mathrm{Fe})$ particles, particularly those with equivalent spherical diameters of greater than $10 \mu \mathrm{m}$, tend to initiate cavities. All $\mathrm{Al}_{6}(\mathrm{Mn}, \mathrm{Fe})$ particles with a diameter of $10 \mu \mathrm{m}$ were found to be adjacent to cavities. The $\mathrm{Mg}-\mathrm{Si}$ particles of all sizes examined are very likely to nucleate cavities. Even $\mathrm{Mg}$-Si particles in the size range 2 to $3 \mu \mathrm{m}$ have a probability greater than 60 pct of residing adjacent to a cavity. These results clearly indicate that a reduction in size of the coarsest $\mathrm{Al}_{6}(\mathrm{Mn}, \mathrm{Fe})$ particles and a reduction or elimination of $\mathrm{Mg}$-Si intermetallic particles will have the beneficial effect of reducing cavitation in AA5083 sheet used for SPF and QPF operations.

\section{ACKNOWLEDGMENTS}

The authors gratefully acknowledge support for this work from General Motors Corporation and from the 
National Science Foundation under DMR No. 0605731.

\section{REFERENCES}

1. A.J. Barnes: J. Mater. Eng. Perform., 2007, vol. 16, pp. 440-54.

2. Z. Li and H. Guo: Mater. Sci. Forum, 2005, vols. 475-479, pp. $3037-42$.

3. D.G. Sanders: Mater. Sci. Forum, 2001, vols. 357-359, pp. 17-22.

4. J.G. Schroth: in Advances in Superplasticity and Superplastic Forming, E.M. Taleff, P.A. Friedman, P.E. Krajewski, R.S. Mishra, and J.G. Schroth, eds., TMS, Warrendale, PA, 2004, pp. 9-20.

5. M.-A. Kulas, W.P. Green, E.M. Taleff, P.E. Krajewski, and T.R. McNelley: Metall. Mater. Trans. A, 2005, vol. 36A, pp. 1249-61.

6. M.-A. Kulas, W.P. Green, E.M. Taleff, P.E. Krajewski, and T.R. McNelley: Metall. Mater. Trans. A, 2006, vol. 37A, pp. 645-55.

7. M.-A. Kulas, P.E. Krajewski, J.R. Bradley, and E.M. Taleff: J. Mater. Eng. Perform., 2007, vol. 16, pp. 308-13.

8. A. Ball and M.M. Hutchison: Met. Sci. J., 1969, vol. 3, pp. 1-7.

9. J.S. Vetrano, C.A. Lavender, C.H. Hamilton, M.T. Smith, and S.M. Bruemmer: Scripta Metall. Mater., 1994, vol. 30, pp. 565-70.

10. P.A. Friedman and A.K. Ghosh: Metall. Mater. Trans. A, 1996, vol. $27 \mathrm{~A}$, pp. 3827-39.

11. H. Iwasaki, H. Hosokawa, T. Mori, T. Tagata, and K. Higashi: Mater. Sci. Eng., A, 1998, vol. 252, pp. 199-202.

12. I.C. Hsiao, J.C. Huang, and S.W. Su: Mater. Trans., JIM, 1999, vol. 40 , pp. $744-53$.

13. R.M. Cleveland, A.K. Ghosh, and J.R. Bradley: Mater. Sci. Eng., A, 2003, vol. 351, pp. 228-36.

14. D. Weinstein: Trans. AIME, 1969, vol. 245, pp. 2041-46.

15. C.W. Humphries and N. Ridley: J. Mater. Sci., 1974, vol. 9, pp. 1429-35.

16. N. Ridley and D.W. Livesey: Res Mech. Lett., 1981, vol. 1, pp. $73-$ 77

17. J.J. Blandin, B. Hong, A. Varloteaux, M. Suery, and G. L'Esperance: Acta Mater., 1996, vol. 44, pp. 2317-26.

18. A.H. Chokshi: Mater. Sci. Eng., A, 2005, vols. 410-411, pp. 95-99.

19. M. Mabuchi, Y. Chino, and H. Iwasaki: Mater. Sci. Forum, 2005, vols. 475-479, pp. 2945-48.

20. D.H. Bae and A.K. Ghosh: Acta Mater., 2002, vol. 50, pp. 511-23.

21. N. Chandra, M.K. Khraisheh, and P. Kalu: Mater. Sci. Forum, 2005, vols. 475-479, pp. 2931-36.

22. C.F. Martin, C. Josserond, L. Salvo, J.J. Blandin, P. Cloetens, and E. Boller: Scripta Mater., 2000, vol. 42, pp. 375-81.

23. H.Q. Yu, J.J. Blandin, and L. Salvo: Mater. Sci. Forum, 2004, vols. 447-448, pp. 55-60.

24. E.M. Taleff, T. Leon-Salamanca, R.A. Ketcham, R. Reyes, and W.D. Carlson: J. Mater. Res., 2000, vol. 15, pp. 76-84.
25. J. Hu, K. Ikeda, and T. Murakami: J. Jpn. Inst. Light Met., 1996, vol. 46, pp. 126-31.

26. Y.S. Sato, S.H.C. Park, and H. Kokawa: Metall. Mater. Trans. A, 2001, vol. 32A, pp. 3033-42.

27. D.H. Bae and A.K. Ghosh: Acta Mater., 2002, vol. 50, pp. $993-$ 1009.

28. C.F. Martin, C. Josserond, L. Salvo, J.J. Blandin, P. Cloetens, and E. Boller: Acta Metall., 2000, vol. 42, pp. 375-81.

29. T.R. McNelley, K. Oh-Ishi, A.P. Zhilyaev, S. Swaminthan, P.E. Krajewski, and E.M. Taleff: Metall. Mater. Trans. A, 2008, vol. 39, pp. 50-64.

30. ASM Specialty Handbook: Aluminium and Aluminum Alloys, J.R. Davids, ed., ASM International, Materials Park, OH, 1993, pp. 3-5.

31. ANSI H35.1. "American National Standard Alloy and Temper Designation Systems for Aluminum," American National Standards Institute, Washington, DC, 2004.

32. ASTM E112-96 (2004) e2. "Standard Test Methods for Determining Average Grain Size," ASTM International, West Conshohocken, PA, 2004.

33. N. Chawla, V.V. Ganesh, and B. Wunsch: Scripta Mater., 2004, vol. 51, pp. 161-65

34. M. Li, S. Ghosh, T.N. Rouns, H. Weiland, O. Richmond, and W. Hunt: Mater. Charact., 1998, vol. 41, pp. 81-95.

35. M.V. Krala, M.A. Manganb, G. Spanosb, and R.O. Rosenberg: Mater. Charact., 2000, vol. 45, pp. 17-23.

36. J.C. Fiala: J. Microsc., 2005, vol. 218, pp. 52-61.

37. J. Hu, K. Ikeda, and T. Murakami: J. Jpn. Inst. Light Met., 1996, vol. 46, pp. 126-31.

38. N. Llorca-Isern, C. Luis-Perez, P.A. Gonzalea, L. Laborde, and D. Patino: Rev. Adv. Mater. Sci., 2005, vol. 10, pp. 473-78.

39. M. Czechowski: J. Mater. Process. Technol., 2005, vols. 164-165, pp. 1001-06.

40. S. Kim, M.P. Balogh, and R.A. Waldo: in Advances in Superplasticity and Superplastic Forming, E.M. Taleff, P.A. Friedman, P.E. Krajewski, R.S. Mishra, and J.G. Schroth, eds., TMS, Warrendale, PA, 2004, pp. 139-49.

41. G. Lucadamo, N.Y.C. Yang, C. San Marchi, and E.J. Lavernia: Mater. Sci. Eng., A, 2006, vol. 430A, pp. 230-41.

42. H. Singh, Y. Mao, A. Sreeranganathan, and A.M. Gokhale: Modell. Simul. Mater. Sci. Eng., 2006, vol. 14, pp. 351-63.

43. K. Marthinsen, J.M. Fridy, T.N. Rouns, K.B. Lippert, and E. Nes: Scripta Mater., 1998, vol. 39, pp. 1177-83.

44. H. Singh, A.M. Gokhale, Y. Mao, and J.E. Spowart: Acta Mater., 2006, vol. 54, pp. 2131-43.

45. A. Tewari, A.M. Gokhale, J.E. Spowart, and D.B. Miracle: Acta Mater., 2004, vol. 52, pp. 307-19.

46. A.D. Rollett, R. Campman, and D. Saylor: Mater. Sci. Forum, 2006, vols. 519-521, pp. 1-10.

47. P.A. Friedman and A.K. Ghosh: Metall. Mater. Trans. A, 1996, vol. 27A, pp. 3827-39. 